\title{
Urine Uric Acid Creatinine Ratio as a Diagnostic and Prognostic Marker of Neonatal Birth Asphyxia
}

\author{
Ashwi R Krishnan ${ }^{\oplus 1}$, Praveen Nayak ${ }^{\oplus 2}$, Sumanth Shetty Bellipady ${ }^{\circledR 3}$, Rathika D. Shenoy ${ }^{\oplus 4}$ \\ ${ }^{1}$ Junior Resident, Department of Paediatrics, K.S Hegde Medical Academy, Nitte, (Deemed to be University), Mangalore, Karnataka, India, ${ }^{2}$ Assistant Professor, \\ Department of Paediatrics, K.S Hegde Medical Academy, Nitte, (Deemed to be University), Mangalore, Karnataka, India, ${ }^{3}$ Professor, Department of Paediatrics, K.S \\ Hegde Medical Academy, Nitte, (Deemed to be University), Mangalore, Karnataka, India, ${ }^{P}$ Professor and Head, Department of Paediatrics, K.S Hegde Medical Academy, \\ Nitte, (Deemed to be University), Mangalore, Karnataka, India.
}

\section{Abstract}

Background: Cerebral hypoxia can result in anaerobic glycolysis which leads to decreased phosphorylase production and increased uric acid which gets excreted in the urine where it can be easily detected. The aim of the study is to assess the utility of urine uric acid creatinine ratio $(\mathrm{UA} / \mathrm{Cr}$ ) as an additional marker of neonatal depression and birth asphyxia and its utility as a potential prognostic indicator for the immediate outcome. Subjects and Methods: It was a case-control study that included 30 newborns born with an APGAR score of less than 7 at 1-min and requiring positive pressure ventilation. Cases were sub-grouped into neonatal depression and birth asphyxia. Newborns with moderate and severe encephalopathy were considered to have an unfavourable outcome. The urine UA/Cr was estimated in both groups. One-way Anova test, Spearman's rho and Receiver Operating Characteristic curve were used for statistical analysis. Results: The mean differences of urine UA/Cr were statistically significant ( $\mathrm{p}=0.011)$ in birth asphyxia (3.02 \pm 1.34$)$, neonatal depression $(2.31 \pm 0.81)$ and controls (2.01 \pm 0.69$)$. A significant negative correlation was seen with APGAR at $1-\min (\mathrm{r}=-0.43 ; \mathrm{p}=0.001)$ and $5-\mathrm{min}(\mathrm{r}=-0.52 ; \mathrm{p}=0.001)$ and umbilical cord blood $\mathrm{pH}(\mathrm{r}=-0.29$; $\mathrm{p}=0.021)$. The mean difference of $\mathrm{UA} / \mathrm{Cr}$ between those with unfavorable (3.23 \pm 1.49$)$ and favourable $(2.14 \pm 0.73)$ outcomes was significant $(\mathrm{p}=0.006)$. A ratio $\geq 2.85$ suggested the unfavourable outcome. Conclusion: The urine $\mathrm{UA} / \mathrm{Cr}$ is a useful diagnostic and prognostic biomarker in newborns with birth asphyxia.

Keywords: Apgar Score, Hypoxic-Ischemic Encephalopathy, Neonatal Depression, Umbilical Cord Blood pH

Corresponding Author: Praveen Nayak, Assistant Professor, Department of Paediatrics, K.S Hegde Medical Academy, Nitte, (Deemed to be University), Mangalore, Karnataka, India.

E-mail: drpraveennayak@gmail.com

Received: 29 March 2020

Revised: 21 April 2020

Accepted: 2 May 2020

Published: 9 July 2020

\section{Introduction}

Neonatal depression is a descriptive term to describe any newborn showing a prolonged transition from intrauterine to extrauterine life. In contrast, birth asphyxia is a distinct term that identifies newborns with an impaired gas exchange or inadequate blood flow leading to persistent hypoxemia, hypercarbia and certain biochemical alterations. ${ }^{[1]}$ Birth asphyxia is one of the major causes of neonatal morbidity and mortality. The incidence of birth asphyxia is 20 per 1000 births in developing countries, up to 10 times higher than in developed countries. Birth asphyxia is associated with mortality of $15-20 \%$ and morbidity of $25 \% .^{[2]}$ The infant's brain is more vulnerable to hypoxic-ischemic injury as vaso-autoregulatory mechanisms are not well developed. In normal babies, oxygen and glucose are the main sources of energy. When cerebral hypoxia occurs, there is a decrease in glucose and Adenosine triphosphate (ATP) production due to anaerobic glycolysis. ${ }^{[3]}$ Only two molecules of ATP are produced compared to thirty-two molecules of ATP during aerobic states. Also, phosphates are catabolized to adenosine, inosine, hypoxanthine and in the presence of xanthine oxidase, further to xanthine and uric acid. These metabolites enter the blood from damaged tissues and are excreted in the urine where they can be easily detected. ${ }^{[4,5]}$

APGAR and umbilical cord blood $\mathrm{pH}$ are commonly used indicators for diagnosis and prognosis of birth asphyxia. The components of the APGAR score are subjective and depend on the maturity of the newborn. ${ }^{[6]}$ The one-minute (1-min) APGAR score helped in assessing the need for immediate intervention; however, current guidelines recommend initiation of resuscitation in the event of neonatal depression. The five-minute (5- 
min) APGAR score tells the effectiveness of resuscitation. ${ }^{[7]}$ Exhaustive studies elucidating the mechanisms of tissue damage in birth asphyxia have been conducted but only few indicators like $\mathrm{pH}$, lactate and base deficit have been studied. Not many studies on early markers of asphyxia and their relation to outcome are available. Markers like xanthine, hypoxanthine and inflammatory cytokines are not routinely done in laboratories.

We studied urine uric acid to creatinine ratio ( $\mathrm{UA} / \mathrm{Cr}$ ), an easily accessible marker, in neonatal depression and birth asphyxia. We also looked at its usefulness in the prognostication of the immediate outcome of these newborns.

\section{Subjects and Methods}

\section{Design}

It was a case-control study conducted at the Newborn and Birthing Units of Departments of Paediatrics and Obstetrics \& Gynaecology of a teaching hospital between January 2018 and June 2019. The study included 30 newborns born with gestational age more than 35 weeks with APGAR score less than 7 at 1-min and requiring positive pressure ventilation as cases. Equal number of newborns matched for gestational age and who did not require resuscitation at birth were recruited as controls. Newborns with major congenital malformations, fetal growth restriction in the antenatal sonogram, small for gestational age babies and newborns born to mothers who received magnesium sulfate or opioids within four hours of labour were excluded in both the groups. The sample size was based on the study by Bhongir et al. ${ }^{[8]}$ It was calculated using online software open-Epi (version 3.0) for 95\% confidence interval $(\mathrm{CI}), 80 \%$ power, $1: 1$ ratio of cases and controls, for the calculated mean difference of 0.69 for urine $\mathrm{UA} / \mathrm{Cr}$.

The Institutional Ethical Committee clearance was obtained before the initiation of the study. Written informed consent was obtained from either of the parents.

\section{Clinical data}

The gestational age, maternal complications during pregnancy, drug history, mode of delivery, and meconium staining of amniotic fluid were recorded. APGAR score at 1-min and 5min, details of resuscitation and birth weight were included. All newborns were followed up for the development of seizure and encephalopathy until discharge from the neonatal intensive care unit. The Sarnat and Sarnat classification was used for the staging of encephalopathy. ${ }^{[9]}$

\section{Laboratory Analysis}

Umbilical cord blood $\mathrm{pH}$ was done in all at birth and urine uric acid and urine creatinine within 24 hours of birth. Cord $\mathrm{pH}$ was estimated by the colorimetric method using the Cobas b 121 automated machine. Urine uric acid $(\mathrm{mg} / \mathrm{dl})$ was estimated by an enzymatic colorimetric method and urine creatinine $(\mathrm{mg} / \mathrm{dl})$ by buffered Jaffe's reaction using automated Cobas c 311 .

\section{Definitions}

\section{The following definitions were used in the study:}

Neonatal depression was defined as any newborn requiring resuscitation with positive pressure ventilation at birth and umbilical cord blood $\mathrm{pH}>7$. Birth asphyxia was a subgroup of the babies with depression at birth and APGAR score $<7$ at 5 -min despite resuscitation or umbilical cord blood $\mathrm{pH} \leq 7.0$. The immediate outcome was considered as unfavorable when newborns had evidence of stages 2 (moderate) or 3 (severe) hypoxic-ischemic encephalopathy (HIE) according to Sarnat and Sarnat classification. ${ }^{[9]}$

\section{Study Outcomes}

The primary outcome was to see the utility of urine $\mathrm{UA} / \mathrm{Cr}$ as a marker to identify birth asphyxia in newborns requiring resuscitation and whether it could be a prognostic indicator for the immediate outcome. The secondary outcome was to obtain a urine $\mathrm{UA} / \mathrm{Cr}$ value that would indicate the unfavourable outcome.

\section{Statistical Analysis}

The software Statistical Package for Social Sciences version 22.0 (IBM SPSS, USA) was used for analysis. Demography data were expressed in frequency and percentage or median. The study group was divided into three: infants with neonatal depression, birth asphyxia and none. The KolmogorovSmirnov test was used to establish a normal distribution of cord $\mathrm{pH}$ and urine $\mathrm{UA} / \mathrm{Cr}$ data across the three groups. A comparison of the mean difference between the groups was done by student t-test and ANOVA. Spearman's rho was used to determine the correlation between urine UA/Cr, APGAR, umbilical cord $\mathrm{pH}$, and immediate neonatal outcome. The receiver operating characteristic curve (ROC) was used to determine the cut off value of urine $\mathrm{UA} / \mathrm{Cr}$ for a favourable outcome that included control newborns. A p-value $<0.05$ was considered statistically significant.

\section{Results}

[Table 1] gives the demography and risk factors for neonatal depression in the study population. Median gestational age in the cases and control groups was 39 weeks and 38 weeks respectively. The median birth weight in the case group (2990g) and the control group (3120 g) were comparable. Among the cases, $70 \%(\mathrm{n}=21)$ had neonatal depression and $30 \%(n=9)$ had birth asphyxia. Comparison of mean differences of umbilical cord $\mathrm{pH}$ and mean differences of urine $\mathrm{UA} / \mathrm{Cr}$ among the three groups were statistically significanc[Table 2]. A urine $\mathrm{UA} / \mathrm{Cr}$ value of $\geq 2.63$ distinguished neonatal depression and birth asphyxia with sensitivity of 
Table 1: Demographic data of studypopulation.

\begin{tabular}{|c|c|c|}
\hline Parameters & Cases $n=30(\%)$ & Controls $n=30(\%)$ \\
\hline $\begin{array}{l}\text { Maternal risk factors } \\
\text { Cephalopelvic disproportion } \\
\text { Maternal fever } \\
\text { Pre-eclampsia } \\
\text { Diabetes Mellitus }\end{array}$ & $\begin{array}{l}7(23.3) \\
4(13.3) \\
4(13.3) \\
1(3.3)\end{array}$ & $\begin{array}{l}1(3.3) \\
1(3.3) \\
- \\
-\end{array}$ \\
\hline $\begin{array}{l}\text { Neonatal risk factors } \\
\text { Late preterm } \\
\text { Meconium stained liquor } \\
\text { Neonatal sepsis }\end{array}$ & $\begin{array}{l}6(20.0) \\
8(26.6) \\
5(16.6)\end{array}$ & $\begin{array}{l}6(20.0) \\
- \\
-\end{array}$ \\
\hline $\begin{array}{l}\text { Mode of delivery } \\
\text { Vaginal delivery } \\
\text { Cesarean delivery } \\
\text { Assisted deliveries }\end{array}$ & $\begin{array}{l}16(53.3) \\
9(30.0) \\
5(16.6)\end{array}$ & $\begin{array}{l}8(26.6) \\
22(73.4) \\
-\end{array}$ \\
\hline $\begin{array}{l}\text { Encephalopathy } \\
\text { None } \\
\text { Stage } 1 \\
\text { Stage } 2 \\
\text { Stage } 3 \\
\text { Seizure } \\
\text { Death }\end{array}$ & $\begin{array}{l}22(73.3) \\
2(6.6) \\
2(6.6) \\
4(13.3) \\
5(16.6) \\
2(6.6)\end{array}$ & $\begin{array}{l}- \\
- \\
-\end{array}$ \\
\hline
\end{tabular}

Table 2: Comparison of newborn asphyxia parameters.

\begin{tabular}{|c|c|c|c|c|}
\hline \multirow[t]{2}{*}{ Parameter } & \multicolumn{3}{|c|}{ Mean \pm Standard deviation } & \multirow[t]{2}{*}{ p-value* } \\
\hline & Control & Newborn depression & Birth asphyxia & \\
\hline $\begin{array}{l}\text { Urine uric } \\
\text { acid/creatinine }\end{array}$ & $2.01 \pm 0.69$ & $2.31 \pm 0.81$ & $3.02 \pm 1.34$ & 0.011 \\
\hline $\begin{array}{l}\text { Umbilical cord blood } \\
\mathrm{pH}\end{array}$ & $7.32 \pm 0.31$ & $7.1 \pm 0.72$ & $7.03 \pm 0.12$ & 0.001 \\
\hline
\end{tabular}

\begin{tabular}{|c|c|c|c|}
\hline \multirow[t]{2}{*}{ Parameter } & \multicolumn{2}{|c|}{ Mean \pm Standard deviation } & \multirow[t]{2}{*}{ p-value* } \\
\hline & $\begin{array}{l}\text { Unfavorable Out- } \\
\text { come }\end{array}$ & Favorable Outcome & \\
\hline Urine uric acid/creatinine & $3.23 \pm 1.49$ & $2.14 \pm 0.73$ & 0.006 \\
\hline Umbilical cord blood $\mathrm{pH}$ & $7.11 \pm 0.13$ & $7.25 \pm 0.11$ & 0.002 \\
\hline
\end{tabular}

\footnotetext{
*Independent sample $t$ test
} 
$66.7 \%$ and 1 -specificity of $23.8 \%\{\mathrm{AUC}=0.65[95 \% \mathrm{CI}(0.42$ $0.88)$ ]; $\mathrm{p}=0.197\}$. Urine $\mathrm{UA} / \mathrm{Cr}$ showed a significant negative correlation with APGAR at $1-\min (\mathrm{r}=-0.43 ; \mathrm{p}=0.001)$ and APGAR at $5-\min (r=-0.52 ; \mathrm{p}=0.001)$. Similarly, the ratio also showed a significant negative correlation with umbilical cord blood $\mathrm{pH}(\mathrm{r}=-0.296 ; \mathrm{p}=0.021)$. Among the newborns with neonatal depression $(n=21)$, about $28.6 \%(n=2)$ had an unfavourable outcome. In newborns fulfilling criteria of birth asphyxia $(\mathrm{n}=9)$, nearly $71.4 \%(\mathrm{n}=5)$ had an unfavourable outcome. [Table 3] shows that among the newborns with unfavorable and favorable outcomes, there was a statistically significant difference in mean urine $\mathrm{UA} / \mathrm{Cr}$ and mean umbilical cord $\mathrm{pH}$. The urine UA/Cr cut off of $\geq 2.85$ had the best sensitivity $(71.4 \%)$ and least false positivity $(15.1 \%)$ for unfavorable outcome $[\mathrm{AUC}=0.74 ; 95 \% \mathrm{CI}(0.50-0.98)]$ with $\mathrm{p}=0.040$.

\section{Discussion}

The results of the present study showed that the urine $\mathrm{UA} / \mathrm{Cr}$ was significantly different among the newborns with neonatal depression, birth asphyxia, and controls. A significant negative correlation between the ratio and the APGAR score and umbilical cord blood $\mathrm{pH}$ was also present. There was also a significant difference based on the neonatal outcome with a threshold value. The mean difference of urine $\mathrm{UA} / \mathrm{Cr}$ in the cases was compared with a few other studies. In the study by Kumar et al. ${ }^{[10]}$ the mean urine $\mathrm{UA} / \mathrm{Cr}$ was found to be statistically higher in asphyxiated babies $(2.58 \pm 1.09 ; \mathrm{p}<0.001)$. However, this study did not determine the correlation between the urine $\mathrm{UA} / \mathrm{Cr}$ and other asphyxia parameters or severity of asphyxia.

Basu et al. ${ }^{[1]}$ showed a statistically significant higher urine $\mathrm{UA} / \mathrm{Cr}$ in asphyxiated newborns $(3.1 \pm 1.3 ; \mathrm{p}<0.001)$ as well as a significant negative correlation with the APGAR score ( $\mathrm{r}$ $=-0.857 ; \mathrm{p}<0.001)$. Palit et al. ${ }^{[12]}$ study showed a moderate negative correlation between the ratio and umbilical cord blood $\mathrm{pH}(\mathrm{r}=-0.55 ; \mathrm{p}<0.001)$. There are not many studies that determine the utility of $\mathrm{UA} / \mathrm{Cr}$ as a marker for the outcome. Choudhary et al. ${ }^{[13]}$ proved a significant positive correlation between the urine $\mathrm{UA} / \mathrm{Cr}$ and different stages of HIE classified according to Sarnat and Sarnat staging. Urine $\mathrm{UA} / \mathrm{Cr}$ was significantly higher in severe HIE $(3.61 \pm 0.61)$ when compared to neonates with moderate HIE $(2.95 \pm 0.98)$ and mild HIE $(2.64 \pm 0.25)$ with a $\mathrm{p}<0.001$.

Though APGAR at 1-min has been in use for decades, neonatal resuscitation is aimed at providing skilled care during the golden minute. We showed that there is an increasing trend in urine $\mathrm{UA} / \mathrm{Cr}$ with neonatal depression and birth asphyxia and negative correlation with cord $\mathrm{pH}$ which is the gold standard. A threshold value for immediate outcome was also obtained. These are some of the novelties of this study. Our study is a single centered study with limited sample size. Long term outcome was not determined. To conclude urine $\mathrm{UA} / \mathrm{Cr}$ is a useful diagnostic and prognostic biomarker in newborns with birth asphyxia.

\section{Conclusion}

The urine $\mathrm{UA} / \mathrm{Cr}$ is a useful diagnostic and prognostic biomarker in newborns with birth asphyxia.

\section{References}

1. Millar LJ, Shi L, Hoerder-Suabedissen A, Molnár Z. Neonatal Hypoxia Ischaemia: Mechanisms, Models, and Therapeutic Challenges. Front Cell Neurosci. 2017;11:78. Available from: https://dx.doi.org/10.3389/fncel.2017.00078.

2. Odd D, Heep A, Luyt K, Draycott T. Hypoxic-ischemic brain injury: Planned delivery before intrapartum events. J Neonatal Perinatal Med. 2017;10(4):347-353. Available from: https: //dx.doi.org/10.3233/npm-16152.

3. Bonifacio SL, Gonzalez F, Ferriero DM. Central nervous system injury and neuroprotection. In: CA G, SU D, editors. Avery's disease of the newborn. Elsevier; 2012. p. 874-879.

4. Rich PR. The molecular machinery of Keilin's respiratory chain. Biochem Soc Trans. 2003;31(6):1095-1105. Available from: https://dx.doi.org/10.1042/bst0311095.

5. Krishnana E, Ponnusamy V, Sekar SP. Study of urinary uric acid and creatinine ratio as a marker of neonatal asphyxia for babies born in a tertiary care hospital. Int J Res Med Sci. 2017;5(12):5418-5418. Available from: https://dx.doi.org/10. 18203/2320-6012.ijrms20175466.

6. Use and abuse of the Apgar score. Committee on Fetus and Newborn, American Academy of Pediatrics, and Committee on Obstetric Practice, American College of Obstetricians and Gynecologists. Pediatrics. 1996;98(1):141-142.

7. Wyckoff MH, Aziz K, Escobedo MB, Kapadia VS, Kattwinkel J, Perlman JM. American Heart Association guidelines update for cardiopulmonary resuscitation and emergency cardiovascular care. Pediatrics. 2015;13(2):196-218. Available from: https://dx.doi.org/10.1542/peds.2015-3373G.

8. Bhongir AV, Yakama A, Saha S, Radia SB, Pabbati J. The urine uric acid/creatinine ratio is an adjuvant marker for perinatal asphyxia. Eur J Pharm Med Res. 2015;2(5):520-528.

9. Sarnat HB, Sarnat MS. Neonatal encephalopathy following fetal distress. A clinical and electroencephalographic study. Arch Neurol. 1976;33(10):696-705. Available from: https: //dx.doi.org/10.1001/archneur.1976.00500100030012.

10. Kumar DD, Chaudhari D, Kumar DA, Kamal DS. Urine uric acid and creatinine ratio as a marker of perinatal asphyxia. ISOR-J Dent Med Sci. 2016;15(6):13-15. Available from: https://dx.doi.org/10.7860/JCDR/2017/22697.9267.

11. Basu P, Som S, Choudhuri N, Das H. Correlation between Apgar score and urinary uric acid to creatinine ratio in perinatal asphyxia. Ind J Clin Biochem. 2008;23(4):361-364. Available from: https://dx.doi.org/10.1007/s12291-008-0079-2.

12. Palit S, Wilar R, Runtunuwu A, Lolombulan J. Blood $\mathrm{pH}$ and urinary uric acid-creatinine ratio in newborns with asphyxia. 
Paediatr Indones. 2016;55(6):352-352. Available from: https: //dx.doi.org/10.14238/pi55.6.2015.352-6.

13. Choudhary L, Palsania S, Berwal PK, Sauparna C, Maheshwari

A. Study of Urinary Uric Acid and Creatinine Ratio as a Marker of Perinatal Asphyxia and Its Correlation with Different Stages of Hypoxic Ischemic Encephalopathy. Preg Child Health. 2017;04(03):12-18. Available from: https://dx.doi.org/ 10.4172/2376-127x.1000336.

Copyright: (C) the author(s), 2020. It is an open-access article distributed under the terms of the Creative Commons Attribution License (CC BY 4.0), which permits authors to retain ownership of the copyright for their content, and allow anyone to download, reuse, reprint, modify, distribute and/or copy the content as long as the original authors and source are cited.

How to cite this article: Krishnan AR, Nayak P, Bellipady SS, Shenoy RD. Urine Uric Acid Creatinine Ratio as a Diagnostic and Prognostic Marker of Neonatal Birth Asphyxia. Asian J. Clin. Pediatr. Neonatol. 2020;8(2):6-10.

DOI: dx.doi.org/10.47009/ajcpn.2020.8.2.2

Source of Support: Nil, Conflict of Interest: None declared. 